\title{
Perda Auditiva Induzida por Ruído Pode Gerar Indenização por Danos Morais e Materiais?
}

\author{
Andréa Cintra Lopes ${ }^{1 *}$, Ana Luisa Vieira Sant'anna ${ }^{1}$, Amanda Bozza ${ }^{1}$, Simone Cristina Chiodi \\ Prestes $^{1,2}$, Graziella Simeão Munhoz ${ }^{1}$ \\ ${ }^{1}$ Departamento de Fonoaudiologia da Faculdade de Odontologia de Bauru (FOB), Universidade de São Paulo \\ ${ }^{2}$ Departamento de Fisioterapia da Universidade Paulista, Campus Bauru, São Paulo \\ * Autora para correspondência: aclopes@usp.br
}

\section{RESUMO}

A literatura aponta iniciativas de mudança no currículo que exigem uma demanda de pesquisas capazes de abordarem a complexidade desses processos, buscando currículos mais integrados e uso de metodologias ativas de aprendizagem. O presente relato integra a disciplina de Saúde Coletiva IV: Fonoaudiologia Relacionada ao Trabalho, ofertada regularmente no Departamento de Fonoaudiologia aos graduandos do terceiro ano do curso de Fonoaudiologia da Faculdade de Odontologia de Bauru da Universidade de São Paulo. Entre muitas das estratégias propostas para essa disciplina, o júri simulado foi selecionado, uma vez que leva em conta a possibilidade de inúmeras operações de pensamento, como: defesa de ideias, argumentação, julgamento, tomada de decisão etc. A opção pelo uso dessa estratégia considerou que o tema em questão é amplamente discutido no âmbito jurídico, uma vez que o artigo 21 da Lei n. 8.213/1991 se refere a qualquer causa que haja contribuído diretamente para a redução ou perda da capacidade para o trabalho; mas, principalmente, porque essa estratégia permite que o estudante envolva todos os momentos de construção do conhecimento, da mobilização à síntese, pela sua característica de possibilitar o envolvimento de um número elevado de estudantes, sendo necessário elaborar uma apresentação concisa, clara e lógica das ideias, com profundidade dos conhecimentos e argumentação fundamentada na literatura. A estratégia selecionada atingiu o objetivo proposto pela disciplina, e a dinâmica agradou aos participantes. Mais especificamente, demonstrou que os estudantes fizeram a análise crítica e reflexiva do conteúdo trabalhado, foram capazes de elaborar conceitos e ampliaram sua autonomia intelectual, responsabilizando-se, assim, pelo seu aprendizado. $\mathrm{O}$ tema divergente despertou o interesse pela ética profissional.

Palavras-Chave: Metodologias Ativas; Ensino-Aprendizagem; Fonoaudiologia; Júri Simulado.

\begin{abstract}
The literature points to initiatives that aim curriculum modifications, which demand research about the complexity of these processes, seeking more integrated curricula and the use of active learning methodologies. This report is part of the Collective Health IV course: Work-Related Speech-Language Pathology, regularly offered at the Department of Speech-Language Pathology and Audiology, to the 3rd-year undergraduate students of Speech Therapy at the Faculty of Dentistry of Bauru-University of São Paulo. Among many of the strategies proposed for this discipline, the simulated jury was selected, since it takes into account the possibility of innumerable thought operations, such as: defense of ideas, argumentation, judgment, decision making etc. The use of this strategy considered that the topic in question is widely discussed in the legal scope, since the 21th article of Law $\mathrm{n}$. $8.213 / 1991$ refers to any cause that has directly contributed to the reduction or loss of capacity for work, but mainly because this strategy allows the student to involve all moments of knowledge construction, from mobilization to synthesis, for its characteristic of involving a large number of students, and it is necessary to elaborate a concise, clear and logical presentation of ideas, depth of knowledge and reasoning based on the literature. The selected strategy reached the objective proposed by the discipline and the dynamics pleased the participants. The students were responsible for their learning; they did the critical and reflexive analysis: elaborating concepts and promoting their intellectual autonomy. The divergent theme aroused interest in professional ethics.
\end{abstract}

Keywords: Active Methodologies; Teaching-Learning; Speech Therapy; Simulated Jury. 


\section{Introdução}

$\mathrm{O}$ presente relato diz respeito à disciplina de Saúde Coletiva IV: Fonoaudiologia Relacionada ao Trabalho, ofertada regularmente no Departamento de Fonoaudiologia aos graduandos do terceiro ano do curso de Fonoaudiologia da Faculdade de Odontologia de Bauru-Universidade de São Paulo.

A literatura aponta iniciativas de mudança no currículo, que exigem uma demanda de pesquisas que abordem a complexidade desses processos, que têm sido mais prevalentes nos cursos de Medicina e Enfermagem, buscando currículos mais integrados e uso de metodologias ativas de aprendizagem. Estudos nessa área são escassos na Fonoaudiologia, embora as Sociedades Científicas, assim como a Universidade de São Paulo, tenham incentivado tais iniciativas.

De acordo com Vasconcelos (2007), ser professor é uma das atividades mais complexas do ser humano, uma vez que implica propiciar a aproximação crítica e significativa do conhecimento construído historicamente como mediação para a formação de uma consciência cidadã, para a construção de uma sociedade digna, solidária e justa para todos.

Observa-se que em algumas Instituições de Ensino Superior - IES - prevalece, em consonância com o modelo tradicional, uma prática docente que carrega concepções de aprendizagem de transmissão-recepção de conhecimento (ZANCHET \& FAGUNDES, 2012). Nessa visão de "ensino", o professor fala, o aluno anota e memoriza, tornando-se assim uma transmissão de informações. Nos últimos anos, as técnicas de ensino-aprendizagem têm sido tão valorizadas quanto os conteúdos. Diante disso, buscam-se novas metodologias para ensino-aprendizagem, valorizando a autonomia do estudante.

As metodologias ativas de ensino-aprendizagem compartilham uma preocupação, porém não se pode afirmar que sejam uniformes do ponto de vista dos pressupostos teórico-metodológicos; assim, identificam-se diferentes modelos e estratégias para sua operacionalização, constituindo alternati- vas para o processo de ensino-aprendizagem, com diversos benefícios e desafios (PAIVA et al., 2016).

Entende-se que as metodologias ativas colocam o estudante diante de problemas e/ou desafios que mobilizam o seu potencial intelectual, enquanto estuda para compreendê-los e/ou superá-los (BERBEL, 2011). De acordo com Saint-Onge, 2001, o vínculo entre aprendizagem e ensino não é causal, ou seja, o ensino não causa aprendizagem nem desenvolve novas capacidades que podem levar à aprendizagem. A aprendizagem necessita do saber reconstruído pelo próprio sujeito.

A partir de muitas reflexões, surgiu o termo ensinagem. Trata-se de uma ação de ensino da qual resulta a aprendizagem do estudante, superando o simples falar por parte do professor (VASCONCELOS, 2007). Nessa superação da exposição tradicional como única forma de explicar é que se inserem as estratégias de ensinagem. Estas possibilitam o pensar, situação em que cada estudante passa a reelaborar as relações dos conteúdos (ANASTASIOU \& ALVES, 2009).

Nesse panorama, destaque ainda para a proposta "Indagação Dialógica Problematizadora - IDP", fundamentada nas concepções construtivistas, a qual parte do pressuposto de que a construção e a reconstrução do conhecimento em sala de aula requerem um intercâmbio constante entre os participantes do processo e deles com o conhecimento (DE LONGHI et al., 2014).

Entre muitas das estratégias propostas para essa disciplina, como a aula expositiva dialogada, estudo de textos, estudo dirigido, solução de problemas, estudo de caso e estudo do meio, selecionou-se o júri simulado, uma vez que leva em consideração a possibilidade de inúmeras operações de pensamento, como: defesa de ideias, argumentação, julgamento, tomada de decisão etc. (KRASILCHIK, 2008). Sua preparação é de intenso envolvimento: abrange todos os momentos da construção do conhecimento, da mobilização à síntese, pela sua característica de possibilitar a participação de um número elevado de estudantes.

De acordo com Apebitense et al. (2014), o júri simulado consiste em uma atividade multidisciplinar 
em que se simula um tribunal judiciário no qual os participantes assumem funções estabelecidas. Permite que questões divergentes sejam discutidas, desenvolvendo senso crítico nos estudantes e que ampliem suas habilidades e competências com relação à capacidade de falar em público, à organização de ideias, à argumentação, à persuasão.

\section{Desenvolvimento}

O programa de aprendizagem da disciplina possibilitou o desenvolvimento de algumas habilidades e competências, como: compreensão do processo saúde-doença-ambiente, políticas públicas de saúde e segurança no trabalho, comunicação, gerência e liderança.

Algumas questões norteadoras foram levantadas, como: o conceito de acidente de trabalho, trazido pela lei 8.213/01, artigo 19, e a descrição de doença profissional e doença do trabalho, no artigo 20 da mesma lei. Por que há dificuldade no reconhecimento e na comprovação da Perda Auditiva Induzida por Ruído (PAIR) ou Perda Auditiva Induzida por Níveis de Pressão Sonora Elevado (PAINPSE) para a concessão do benefício previdenciário?

O ruído ocupacional é apontado como a principal causa da PAIR/ PAINPSE, que é reconhecida pela legislação brasileira como doença ocupacional. Toda e qualquer forma de prejuízo à saúde do trabalhador deve compor a gama de preocupações de todos os setores relacionados à saúde e à segurança no trabalho. No Brasil, a Portaria do INSS, as Normas Regulamentadoras (NR) relatam sobre a PAIR e o Programa de Conservação da Audição (PCA). Segundo essas diretrizes, a organização do PCA é de responsabilidade da empresa e envolve uma equipe multiprofissional.

A PAIR/PAINPSE, por ser uma doença ocupacional, apresenta certas peculiaridades e questões complicadas, tais como: a necessidade de estabelecer seu nexo causal, de realizar um diagnóstico diferencial e um laudo pericial.

Consideradas tragédias sociais, uma vez que tiram a capacidade dos trabalhadores para exercerem suas atividades, as doenças ou acidentes relacionados ao trabalho fazem parte da realidade deles. Entretanto, para a concessão de benefícios exigem-se a comprovação da incapacidade para o trabalho e o nexo de causalidade com a atividade exercida pelo trabalhador. Quanto a acidentes típicos, essa constatação é mais fácil; no entanto, em se tratando de atípicos ou de doenças ocupacionais, há muitas dificuldades para comprovar o dano e aferir o benefício.

$\mathrm{Na}$ atividade proposta para o júri simulado, o trabalhador relatou que teve a perda auditiva decorrente do trabalho e que solicitou indenização. Para o reconhecimento da responsabilidade da empresa, houve necessidade de evidenciar o nexo causal entre a doença (PAIR/PAINPSE) e o trabalho prestado, com prevalência das conclusões extraídas do laudo pericial.

A partir do diagnóstico de Perda Auditiva Sensorioneural Bilateral Simétrica, os estudantes, no ano de 2015, realizaram o júri simulado. Os estudantes receberam o tema proposto pelo professor (Anexo 1), e os papéis foram divididos de acordo com a função específica de cada integrante de um julgamento, ou seja: juiz, coordenação, defesa, promotoria, testemunhas e jurados. Os estudantes se prepararam para defender o tema com argumentos convincentes. Então, a disciplina selecionou oito horas, a fim de se realizar a reunião entre os grupos, para que os argumentos fossem levantados. Esse tempo inicial para os estudantes foi necessário, para que os mesmos socializassem suas informações em grupo antes do debate.

A partir daí, cada estudante pôde lançar a sua tese inicial, defender seu ponto de vista, argumentar, testemunhar e apresentar as "provas". Depois de cada segmento, houve um tempo para as considerações finais. Por fim, o juiz lançou o problema principal; a defesa apresentou seus argumentos (escritos pelo grupo nas oito horas destinadas para tal); a promotoria apresentou seus argumentos; as testemunhas da defesa, assim como as testemunhas da promotoria, participaram ativamente na elaboração dos argumentos. Estava ainda presente o júri popular, formado por alunos da pós-graduação e do programa de prática profissionalizante que 
acompanham o professor nessa disciplina; eles foram imparciais.

O juiz organizou o tempo para as falas e cronometrou o destinado às réplicas e tréplicas. $\mathrm{O}$ júri popular em conjunto com o juiz, após todo o caso ser debatido, deu a sentença.

O professor, como coordenador da atividade, com a participação de alguns pós-graduandos, lançou questionamentos, motivando o debate, evitando fornecer respostas ou apoiar alguma das posições, até que o júri popular socializou seus apontamentos e o juiz decretou o veredicto.

No final da atividade, os estudantes responderam as seguintes questões: Que proveito tirei da dinâmica? O que mais me agradou? Como me senti? O que posso melhorar?

\section{Resultados e Discussão}

A opção por essa estratégia considerou que o tema em questão é amplamente discutido no âmbito jurídico, uma vez que o artigo 21 da lei n. 8.213/1991 se refere a qualquer causa que haja contribuído diretamente para a redução ou perda da capacidade de trabalho, mas, principalmente, porque essa estratégia permite que o estudante articule todos os momentos de construção do conhecimento, da mobilização à síntese, pela sua

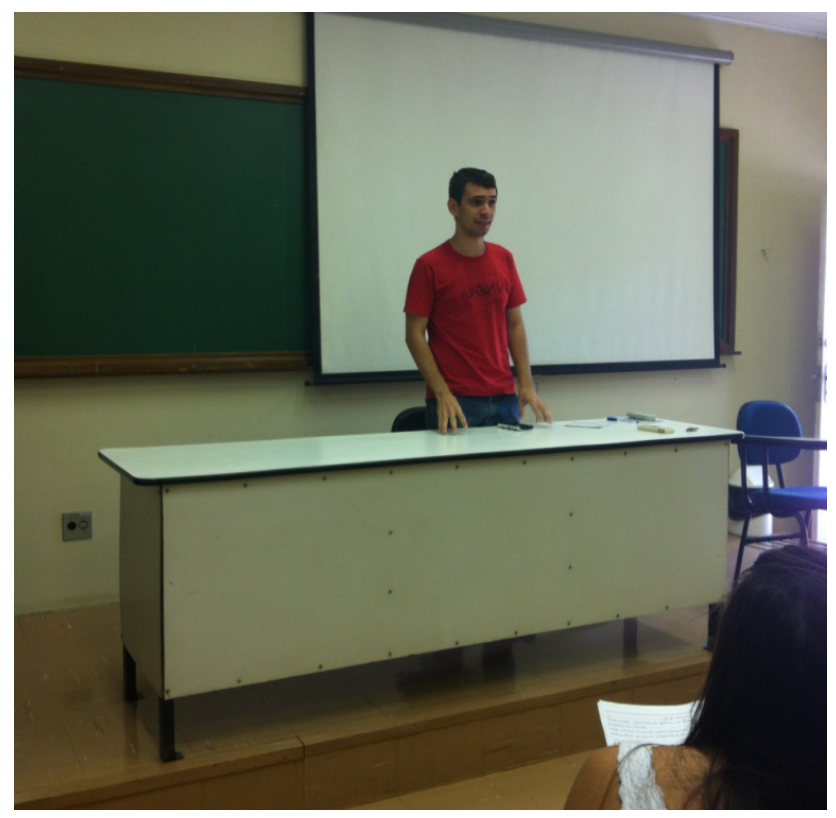

característica de possibilitar o envolvimento de um número elevado de estudantes, sendo necessário elaborar uma apresentação concisa, clara e lógica das ideias, com profundidade dos conhecimentos e argumentação fundamentada na literatura.

A estratégia selecionada atingiu o objetivo proposto pela disciplina e a dinâmica agradou aos participantes. No que diz respeito à aprendizagem construída, os graduandos valorizaram as estratégias utilizadas no decorrer da disciplina, destacando a construção e o planejamento; nos registros coletados, notou-se um estudante reflexivo, envolvido, fazendo sua parte na construção do conhecimento. Observaram-se qualidade na argumentação, percepção aguçada e crítica, capacidade de articulação da teoria e prática, habilidade de organização das respostas com logicidade, clareza e coerência. Os estudantes ampliaram sua autonomia e a qualidade de suas produções, favorecendo a articulação dos conhecimentos, habilidades e atitudes.

Nesse contexto, a aprendizagem aconteceu na parceria do professor com seus estudantes, na aventura do ensinar e aprender. Nesse sentido, constituiu um desafio, um compromisso com a construção do conhecimento. Por tudo isso, consideraram-se as estratégias de ensinagem como desafio para um professor comprometido e inovador.

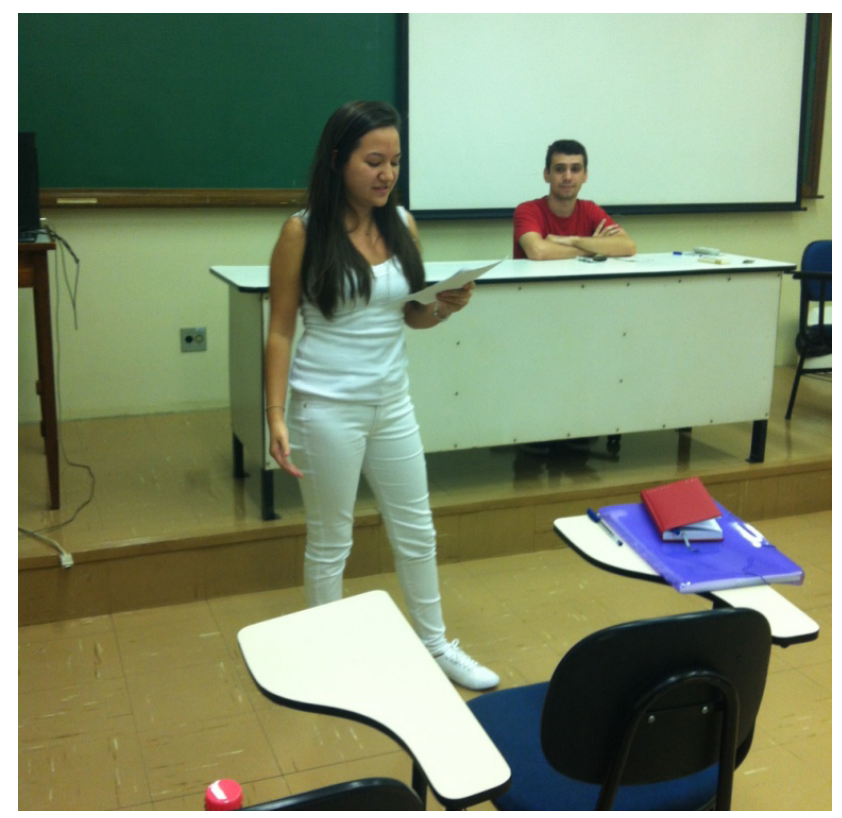

Figura 1 - Juiz (à esquerda) e defesa (à direita). 

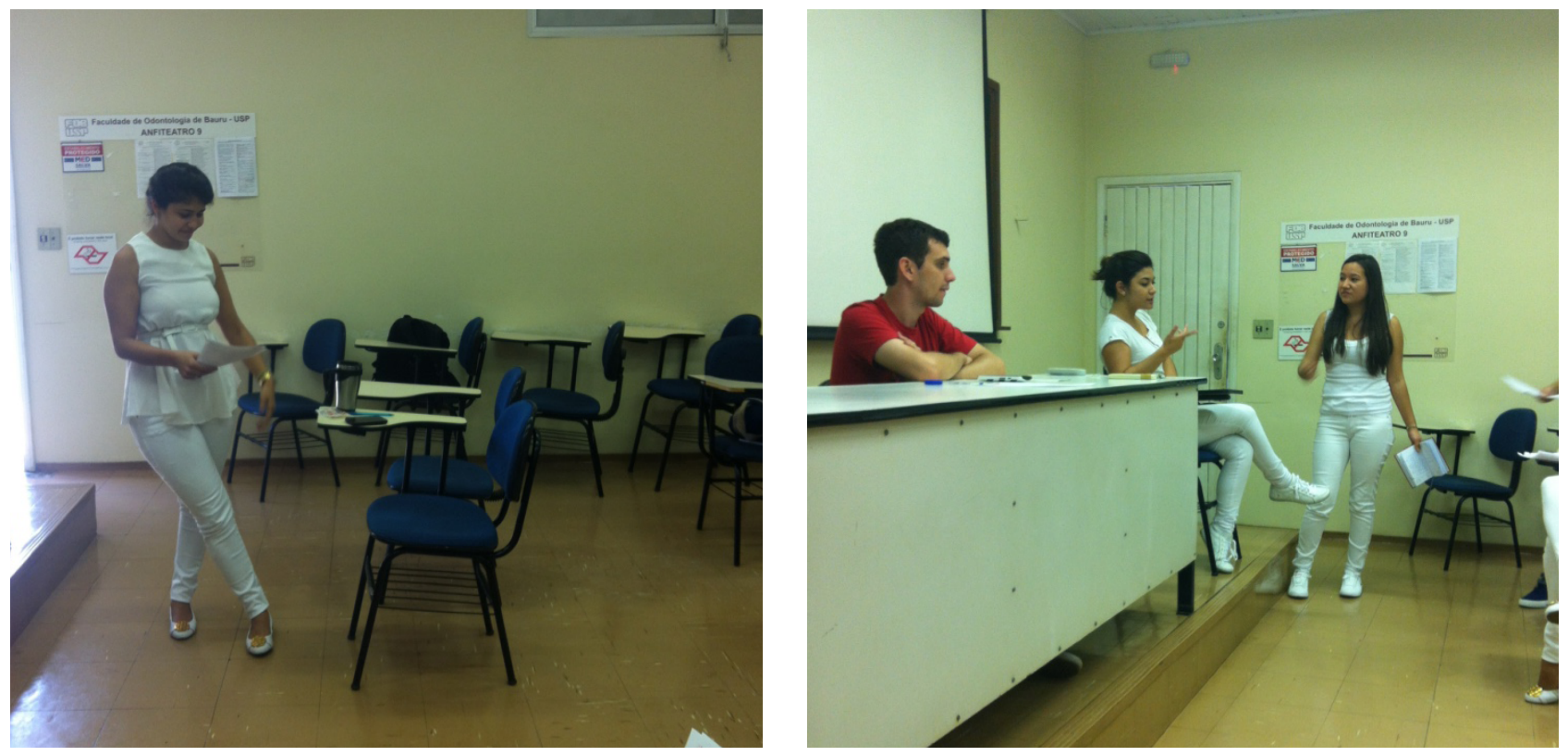

Figura 2 - Promotoria (à esquerda) e testemunha (à direita).

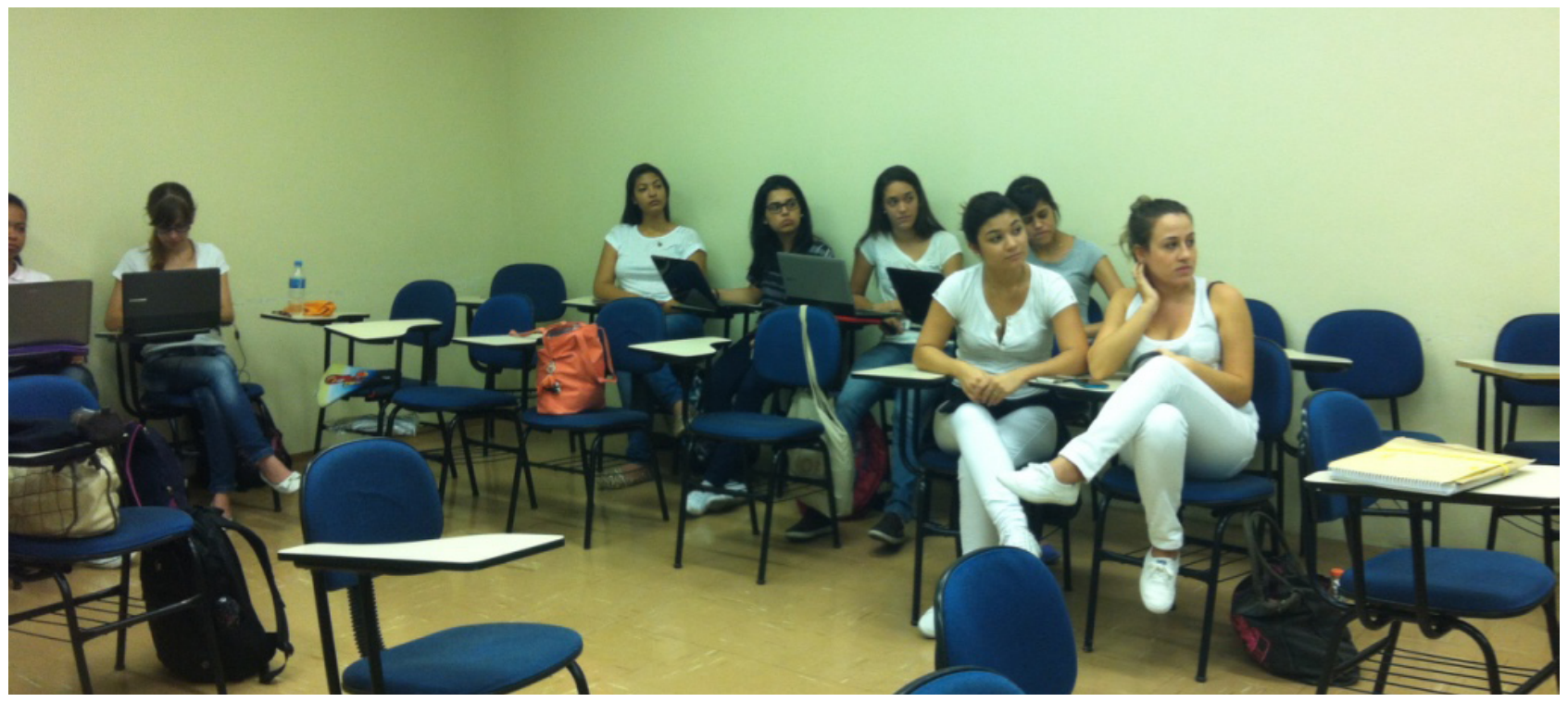

Figura 3 - Jurados.

A experiência com o júri simulado, iniciada em 2012, envolveu todos os estudantes matriculados anualmente nessa disciplina. Os estudantes foram estimulados ao desafio de serem avaliados por meio dessas estratégias de aprendizagem, principalmente pelo júri simulado. No contrato pedagógico, firmado no início do semestre, essa forma de avaliação foi determinada.

Declarada a sentença, os estudantes responderam as seguintes questões: Que proveito tirei da dinâmica? $\mathrm{O}$ que mais me agradou? Como me senti? O que posso melhorar?

De forma geral, os estudantes relataram que a atividade foi mais interessante do que ficar estudando em livros e artigos sobre as perdas auditivas relacionadas ao trabalho. Em relação à primeira questão, "Que proveito tirei da dinâmica?", veio a resposta (E 1): "Foi bem legal, eu fiquei mais motivado, porque tive a responsabilidade de decidir, estudei muito, mais do se fosse estudar para prova...". À questão "Como me senti?", E 3 declarou: "Nossa, nunca estudei tanto, tinha que defender 
uma ideia contrária àquela em que eu acreditava, foi difícil buscar argumentos, conversei com amigos que fazem direito... estudei assuntos de outras áreas... foi muito legal... me senti uma doutora". Em relação à questão "O que posso melhorar?", houve um consenso nas respostas em afirmarem que eles podem se dedicar mais aos estudos sem a presença do professor: "Quando a professora sugeriu alguns temas para começar o estudo, tudo fluiu... eu sei que sou capaz de estudar sozinha, sem ficar só prestando atenção no professor ou estudar só o que eles sugerem" (E 18).

\section{Conclusão}

O júri simulado foi uma estratégia que atingiu os objetivos de aprendizagem da disciplina: demonstrou que os estudantes fizeram a análise crítica e reflexiva, foram capazes de elaborar conceitos e promoveram autonomia intelectual, responsabilizaram-se pelo seu aprendizado. O tema divergente despertou o interesse pela ética profissional.

\section{Referências Bibliográficas}

ANASTASIOU, L. G. C. \& ALVES, L. P. Processos de Ensinagem na Universidade: Pressupostos para as Estratégias de Trabalho em Aula. 8 ed. Joinville, SC: Univille, 2009.

APEBIRENSE, P. G. G. S.; VIEIRA, G. O.; GURTINHAS, S. \& BARBOSA, L. M. A. Articulo 88. Congresso Iberoamericano de Ciencia, Tecnologia, Inovation y Education. Buenos Ayres, 2014. Acessado em 28 nov. 2017.
BERBEL, N. A. M. "As Metodologias Ativas e a Promoção da Autonomia de Estudantes". Semina: Ciências Sociais e Humanas (Serial on the internet), Londrina, vol. 32, n. 1, pp. 25-40, jan./jun. 2011. Disponível em: $<$ http://www.proiac.uff.br/sites/default/files/documentos/berbel_2011.pdf >. Acessado em 15 nov. 2017.

DE LONGHI, A. L.; BERMUDEZ, G. M. A.; ABENSUR, P. L. D. \& RUIZ-MORENO, L. "Una Estrategia Didáctica para la Formación de Educadores de Salud en Brasil: la Indagación Dialógica Problematizadora". Interface (Botucatu), vol. 18, n. 51, pp. 759-69, 2014.

KRASILCHIK, M. "Docência no Ensino Superior: Tensões e Mudanças". Cadernos de Pedagogia Universitária, Faculdade de Educação, Universidade de São Paulo (Feusp), maio 2008.

NORMA REGULAMENTADORA - NR 9. "Programa de Prevenção de Riscos Ambientais". Cap. V, Título II, da CLT. Programa de Prevenção de Riscos Ambientais. Portaria SSST, n. 25, 29 dez. 1994.

PAIVA, M. R. F.; PARENTE, J. R. F.; BRANDÃO, I. R. \& QUEIROZ, A. H. B. "Metodologias Ativas de Ensino Aprendizagem: Revisão Integrativa". Sanare, Sobral, vol. 15, n. 2, pp. 145-153, 2016.

SAINT-ONGE, M. O Ensino na Escola: o que é e como se faz. 2 ed. São Paulo: Loyola. 2001.

VASCONCELOS, G. S. "Competência Docente na Perspectiva de Paulo Freire". Rev Educ AEC, vol. 143, pp. 66-78, 2007.

ZANCHET, B. M. A. \& FAGUNDES, M. V. "A Preparação para o Exercício do Magistério Superior Far-se-á em Nível de Pós-Graduação? Os Docentes Iniciantes Respondem". Rev E-Curriculum, vol. 8, n. 1, pp. 1-21, 2012.

\section{Anexo 1 - Perda Auditiva por Excesso de Ruído no Trabalho Pode Gerar Indenização?}

O reclamante solicita indenização por danos, materiais e morais, devido a doença relacionada ao trabalho, por culpa da reclamada (omissão quanto às medidas necessárias à neutralização do ruído), assim como por perda parcial e permanente de sua capacidade laboral. Solicita o valor de R\$ 100.000,00.

O reclamante, funcionário da limpeza geral, 57 anos, relatou que trabalhou por treze (13) anos em uma empresa com ruído excessivo, acima dos limites recomendados pela NR. Nas audiometrias periódicas foi observada uma progressão da perda auditiva, fato este que o limitou para desempenhar suas atividades laborais e sociais, e principalmente em sua vida em família.

"Diversamente do beneficio previdenciário, a indenização de cunho civil tem por objetivo não apenas o ressarcimento de ordem econômica, mas, igualmente, o de compensar a vítima pela lesão fisica causada pelo ato ilícito do empregador, que reduziu a sua capacidade laboral em caráter definitivo, inclusive pelo natural obstáculo de ensejar a busca por melhores condições e remuneração na mesma empresa ou no mercado de trabalho. Destarte, ainda que paga ao empregado a mesma remuneração anterior por força de cumprimento a acordo coletivo de trabalho, o surgimento 
de sequelas permanentes há de ser compensado pela prestação de pensão desde a data do sinistro, independentemente de não ter havido perda financeira concretamente apurada durante o período de afastamento."

Em conformidade com o laudo pericial, o reclamante usou protetor auricular nos últimos seis anos de contrato e creme protetor para as mãos e o antebraço a partir de 20 de setembro de 1998 (fl. 338). Tendo em vista que, segundo o laudo, a insalubridade existente foi neutralizada pelo uso dos dois EPIs aludidos.

Publicado em 22/12/2017. 